\title{
Computational identification and characterization of glioma candidate biomarkers through multi-omics integrative profiling
}

Lin Liu' ${ }^{1,2,3 \dagger}$, Guangyu Wang ${ }^{1,2,3,4 \dagger}$, Liguo Wang ${ }^{5}$, Chunlei Yu ${ }^{1,2,3}$, Mengwei Li ${ }^{1,2,3}$, Shuhui Song ${ }^{1,2,3}$, Lili Hao ${ }^{1,2,3}$, Lina $\mathrm{Ma}^{1,2,3^{*}}$ and Zhang Zhang ${ }^{1,2,3^{*}}$

\begin{abstract}
Background: Glioma is one of the most common malignant brain tumors and exhibits low resection rate and high recurrence risk. Although a large number of glioma studies powered by high-throughput sequencing technologies have led to massive multi-omics datasets, there lacks of comprehensive integration of glioma datasets for uncovering candidate biomarker genes.

Results: In this study, we collected a large-scale assemble of multi-omics multi-cohort datasets from worldwide public resources, involving a total of 16,939 samples across 19 independent studies. Through comprehensive molecular profiling across different datasets, we revealed that PRKCG (Protein Kinase C Gamma), a brain-specific gene detectable in cerebrospinal fluid, is closely associated with glioma. Specifically, it presents lower expression and higher methylation in glioma samples compared with normal samples. PRKCG expression/methylation change from high to low is indicative of glioma progression from low-grade to high-grade and high RNA expression is suggestive of good survival. Importantly, PRKCG in combination with MGMT is effective to predict survival outcomes in a more precise manner.

Conclusions: PRKCG bears the great potential for glioma diagnosis, prognosis and therapy, and PRKCG-like genes may represent a set of important genes associated with different molecular mechanisms in glioma tumorigenesis. Our study indicates the importance of computational integrative multi-omics data analysis and represents a datadriven scheme toward precision tumor subtyping and accurate personalized healthcare.
\end{abstract}

Keywords: Glioma, Multi-omics, PRKCG, Biomarker, Cerebrospinal fluid

\section{Background}

Glioma, one of the serious central nervous system (CNS) tumors, represents $\sim 80 \%$ of malignant brain tumors $[1,2]$ and exhibits low resection rate and high recurrence risk [3]. Since tumor classification benefits accurate diagnosis

\footnotetext{
* Correspondence: malina@big.ac.cn; zhangzhang@big.ac.cn

${ }^{+}$Lin Liu and Guangyu Wang contributed equally to this work.

${ }^{1}$ China National Center for Bioinformation, Beijing 100101, China

Full list of author information is available at the end of the article
}

and facilitates precise treatment, gliomas can be classified, according to the histologic grading schemes, into LGG (astrocytoma, oligodendroglioma and oligoastrocytoma) and GBM (glioblastoma multiforme) [4]. Therefore, identification of reliable molecular biomarkers for precise classification of different-grade gliomas is crucial to aid tumor diagnosis, establish appropriate therapies, recognize prognostic outcome and predict therapeutic response [5].

C C The Author(s). 2020 Open Access This article is licensed under a Creative Commons Attribution 4.0 International License, which permits use, sharing, adaptation, distribution and reproduction in any medium or format, as long as you give appropriate credit to the original author(s) and the source, provide a link to the Creative Commons licence, and indicate if changes were made. The images or other third party material in this article are included in the article's Creative Commons licence, unless indicated otherwise in a credit line to the material. If material is not included in the article's Creative Commons licence and your intended use is not permitted by statutory regulation or exceeds the permitted use, you will need to obtain permission directly from the copyright holder. To view a copy of this licence, visit http://creativecommons.org/licenses/by/4.0/ The Creative Commons Public Domain Dedication waiver (http://creativecommons.org/publicdomain/zero/1.0/) applies to the data made available in this article, unless otherwise stated in a credit line to the data. 
Powered by high-throughput sequencing technologies, a set of molecular biomarkers have been discovered from different omics levels to assist glioma diagnosis and treatment $[6,7]$. Among them, isocitrate dehydrogenase (IDH) mutation and 1p/19q co-deletion (codel) are two most important genetic events for glioma grading [8-10]. Patients with $I D H$ mutation (IDH-mut) have longer survival than those with $I D H$ wild-type (IDH-WT) $[11,12]$. And the 1p/ $19 \mathrm{q}$ codel is a distinctive feature of oligodendroglioma [13, 14]. Furthermore, based on these two genetic alterations, accumulated evidence suggested that gliomas can be divided into three subtypes (IDH-mut \& 1p/19q codel, $I D H$ mut \& 1p/19q non-codel, and IDH-WT \& 1p/19q noncodel), which are associated with diverse clinical outcomes [15]. Accordingly, in 2016, the World Health Organization (WHO), in light of both histology and significant genetic events (mainly by $I D H$ and $1 \mathrm{p} / 19 \mathrm{q}$ ), divided gliomas into five categories [16, 17], including three LGGs (diffuse astrocytoma, $I D H$-mut \& 1p/19q non-codel; oligodendroglioma, $I D H$-mut \& 1p/19q codel; diffuse astrocytoma, $I D H$ WT \& 1p/19q non-codel) and two GBMs (IDH-mut; IDH-WT). Meanwhile, molecular markers at the transcriptome level have also been identified [18-21]; for example, an overexpression of epidermal growth factor receptor variant III (EGFRvIII) has been reported to associate with malignant progression of GBM [22-24]. In addition, epigenetic modifications are also implicated in glioma [25-29]. One classical biomarker is O6methylguanine-DNA-methyltransferase (MGMT) [30]; patients with methylated MGMT promoter have better clinical outcomes and are more sensitive to the alkylating chemotherapy than those without methylated MGMT promoter [31-33].

Nowadays, there is an increasing number of highthroughput studies for better understanding of glioma tumorigenesis [34-38], resulting in massive multi-omics datasets generated from different projects and laboratories throughout the world. However, there lacks of comprehensive integration of glioma datasets for computationally identifying and characterizing candidate biomarkers. To this end, we collected a large-scale assemble of multiomics multi-cohort datasets from worldwide public resources and detected candidate biomarker genes through comprehensive integrative molecular profiling on multiple independent datasets. We revealed that PRKCG, a gene specifically expressed in brain and detectable in cerebrospinal fluid (CSF), is closely associated with glioma, indicative of a potential biomarker for glioma diagnosis, prognosis and treatment prediction.

\section{Materials and methods}

\section{Data collection}

In this study, we collected a comprehensive assemble of multi-omics datasets (including genomics, transcriptomics,
DNA methylomics and proteomics) from The Cancer Genome Atlas (TCGA, https://portal.gdc.cancer.gov/) [35], Genotype-Tissue Expression Portal (GTEx, https:/gtexportal.org/home/) [39], Gene Expression Omnibus (GEO, https://www.ncbi.nlm.nih.gov/geo), Ivy Glioblastoma Atlas Project (Ivy GAP, http://glioblastoma.alleninstitute.org) [40] and Chinese Glioma Genome Atlas (CGGA, http://www. cgga.org.cn) [41, 42]. Particularly, discovery datasets were derived from TCGA, GTEx and large cohort studies in GEO (GSE83710, GSE16011 and GSE36278 for protein, expression and methylation, respectively). As a result, a total of five discovery datasets and 14 validation datasets were obtained. For convenience, each dataset collected in this study is assigned a unique accession number with the format: [D/V][i]-[TCGA/GTEx/GEO/CGGA/Ivy GAP]$[\mathrm{E} / \mathrm{V} / \mathrm{P} / \mathrm{M}]$, where $\mathrm{D} / \mathrm{V}$ in the first bracket represents the dataset for discovery or validation, $i$ in the second bracket indicates the dataset number, the third bracket shows the data source (as mentioned above), and the last bracket indicates the data type, namely, E for RNA expression, $V$ for $\mathrm{CNV}, \mathrm{P}$ for protein expression and $\mathrm{M}$ for DNA methylation, respectively. The detailed information about all collected datasets was tabulated in Table 1.

\section{Identification of brain-specific genes}

To identify brain-specific genes, we used the RNA-Seq dataset from GTEx (2016-01-15; v7) [39], which contains 11,688 samples across 53 tissue sites of 714 donors. Considering that several tissues have multiple different sites, gene expression levels were averaged over sites that are from the same tissue. To reduce background noise, genes with maximal expression levels smaller than 10 TPM (Transcripts Per Million) were removed. Finally, we obtained a total of 15,176 gene expression profiles across 30 tissues (Additional file 1: Table S1).

Based on the expression levels across 30 tissues, we calculated the tissue specificity index $\tau$ [56] for each gene to identify tissue-specific genes. $\tau$ is valued between 0 and 1, where 0 represents housekeeping genes that are consistently expressed in different tissues, and 1 indicates tissue-specific genes that are exclusively expressed in only one tissue [56]. In this study, brain-specific genes were defined as those genes that are maximally expressed in the brain with $\tau>0.9$. As a consequence, a list of the top 100 brain-specific genes ranked by the $\tau$ index were obtained for further analysis (Additional file 1: Table S2).

\section{Sample classification}

To comprehensively study the potential of PRKCG in glioma diagnosis, we compared the molecular profiles between normal and glioma samples, between LGG and GBM samples, between primary GBM (pGBM) and recurrent GBM (rGBM) samples, and between glioma 
Table 1 Summary of multi-omics multi-cohort glioma datasets

\begin{tabular}{|c|c|c|c|c|c|c|}
\hline Category & Accession number & Source & Omics type & \# Samples & \# Population country/race & Reference \\
\hline \multirow[t]{8}{*}{ Discovery } & D1-GTEx-E & GTEx & Expression (RNA-Seq) & 11,688 & mostly white & [39] \\
\hline & D2-GSE83710-P & GSE83710 & Protein & 133 & Japan & [43] \\
\hline & D3-GSE16011-E & GSE16011 & Expression (Microarray) & 284 & Netherlands & [44] \\
\hline & D4-TCGA-V & TCGA & CNV & 1018 & mostly white & [35] \\
\hline & D4-TCGA-E & TCGA & Expression (RNA-Seq) & 607 & mostly white & {$[35]$} \\
\hline & D4-TCGA-M & TCGA & Methylation $(27 \mathrm{~K}+450 \mathrm{~K})$ & 862 & mostly white & [35] \\
\hline & D4-TCGA-M (TMZ treatment) & TCGA & Methylation $(27 \mathrm{~K}+450 \mathrm{~K})$ & 228 & mostly white & {$[35]$} \\
\hline & D5-GSE36278-M & GSE36278 & Methylation (450 K) & 142 & Germany & [45] \\
\hline \multirow[t]{14}{*}{ Validation } & V1-GSE4290-E & GSE4290 & Expression (Microarray) & 180 & USA & {$[46]$} \\
\hline & V2-GSE50161-E & GSE50161 & Expression (Microarray) & 47 & USA & {$[47]$} \\
\hline & V3-GSE59612-E & GSE59612 & Expression (RNA-Seq) & 92 & USA & {$[48]$} \\
\hline & V4-GSE111260-E & GSE111260 & Expression (Microarray) & 70 & Norway & - \\
\hline & V5-GSE2223-E & GSE2223 & Expression (Microarray) & 54 & USA & {$[49,50]$} \\
\hline & V6-Ivy GAP-E & Ivy GAP & Expression (RNA-Seq) & 122 & unknown & {$[40]$} \\
\hline & V7-CGGA-E & CGGA & Expression (Microarray) & 301 & China & {$[42,51]$} \\
\hline & V8-GSE50923-M & GSE50923 & Methylation (27 K) & 78 & USA & [52] \\
\hline & V9-GSE61160-M & GSE61160 & Methylation (450 K) & 51 & Spain & [53] \\
\hline & V10-CGGA-M & CGGA & Methylation (27 K) & 159 & China & {$[54]$} \\
\hline & V11-TCGA-M & TCGA & Methylation (WGBS) & 6 & white & - \\
\hline & V12-CGGA-E & CGGA & Expression (RNA-Seq) & 310 & China & [41] \\
\hline & V13-CGGA-E & CGGA & Expression (RNA-Seq) & 667 & China & - \\
\hline & V14-GSE60274-M & GSE60274 & Methylation (450 K) & 68 & Switzerland & [55] \\
\hline
\end{tabular}

CGGA Chinese Glioma Genome Atlas, http://www.cgga.org.cn

GEO Gene Expression Omnibus, https://www.ncbi.nlm.nih.gov/geo/

GTEx Genotype-Tissue Expression, https://www.gtexportal.org

TCGA The Cancer Genome Atlas, https://portal.gdc.cancer.gov

Ivy GAP Ivy Glioblastoma Atlas Project, http://glioblastoma.alleninstitute.org

samples with different anatomic features. We collected 122 GBM samples from the Ivy GAP database [40] and grouped them according to their anatomic regions, namely, leading edge (LE, the ratio of tumor/normal cells is about $1-3 / 100$ ), infiltrating tumor (IT, the ratio of tumor/normal cells is about 10-20/100), cellular tumor (CT, the ratio of tumor/normal cells is about 100/1 to 500/1), pseudo-palisading cells around necrosis (PAN, the narrow boundary of cells along the dead tissue), and microvascular proliferation (MVP, two or more blood vessels sharing a common vessel wall of endothelial).

We investigated the prognostic role of PRKCG by dividing samples into subgroups based on PRKCG's expression level within all glioma samples and also within LGG and GBM samples, respectively. When exploring the predictive role of PRKCG, we obtained DNA methylation status (methylated and unmethylated) directly from the original study [35], which was defined based on the beta value cutoff 0.3 .

\section{Identification of PRKCG-like genes}

Genes that satisfy the following criteria were regarded as PRKCG-like genes: (1) Higher methylation level of at least one $\mathrm{CpG}$ site (promoter region) in glioma samples than normal samples; (2) Higher DNA methylation level in LGG samples than GBM samples; (3) Higher expression level in LGG samples than GBM samples; and (4) Lower expression level in glioma samples than normal samples. As a result, we obtained a total of 542 PRKCGlike genes, which were further divided into two groups according to their correlations between gene expression and methylation, namely, 114 genes with negative correlation and 297 genes with positive correlation.

\section{Statistical analysis}

All statistical analyses were performed using $\mathrm{R}$ version 3.3.2. The Wilcoxon test was used for the analysis of the difference in gene expression/methylation between tumor and normal samples, and between different 
glioma subtypes. The statistical significance levels were coded by $n s$ (not significant) $p>0.05, * p<0.05$, *** $p<$ 0.01 and $* * 0<0.001$. We performed the survival analysis using the Kaplan-Meier method and estimated the statistical difference using the log-rank test.

\section{Results and discussion \\ $P R K C G$ is a brain-specific gene and detectable in cerebrospinal fluid}

Tissue-specific genes are believed to be crucial for identifying potential biomarkers with high specificity [57-61]. To identify candidate genes with brain specificity, we integrated expression data from GTEx (D1GTEx-E) [39], explored all genes' expression profiles and their tissue specificity, and identified a list of top 100 brain-specific genes (Additional file 1: Table S2). To achieve the detectability in the periphery, we assembled a total of 1126 CSF-detectable proteins from GEO (D2-GSE83710-P) [43], due to the critical significance of CSF as a feasible means to detect genes expressed in human CNS [62, 63]. After integrating brain-specific genes with CSF proteins, we revealed that there are five brain-specific proteins that can be detected in CSF (Fig. 1 and Additional file 2: Fig. S1), in terms of fluorescence intensity from high to low, namely, PRKCG (protein kinase C gamma), BCAN (brevican), OPCML (opioid binding protein/cell adhesion molecule like), GFAP (glial fibrillary acidic protein) and CAMK2A (calcium/calmodulin dependent protein kinase II alpha), which are diversely expressed in different brain regions (Additional file 3: Fig. S2). Specifically, $B C A N$, a member of the lectican family of chondroitin sulfate proteoglycans, is highly expressed in glioma and may promote cell motility of brain tumor cells $[64,65]$. In addition, the fusion event between BCAN and NTRK1 (BCAN-NTRK1) is a potential glioma driver and therapeutic target [66]. $O P C M L$ encodes a member of the IgLON subfamily in the immunoglobulin proteins and is downregulated in gliomas and other brain tumors [67, 68]. GFAP, encoding one of the major intermediate filament proteins of mature astrocytes [69], can be used to assess the differentiation state of astrocytoma [70]. $C A M K 2 A$ is a calcium calmodulin-dependent protein kinase and reduced expression of $C A M K 2 A$ is associated with better survival in GBM [71, 72].

Remarkably, PRKCG, a member of protein kinase C (PKC) family located in 19q, exhibits higher fluorescence intensity than the other four genes (Fig. 1 and Additional file 2: Fig. S1). The expression profile of PRKCG across multiple brain developmental stages reveals that its expression is extremely lower in the prenatal stages, but dramatically increases in the infancy stages and is stabilized in the latter stages according to GenTree (Additional file 4: Fig. S3) [73]. Previous studies have documented that unlike other PKC family members that are expressed in many tissues aside from brain, $P R K C G$ is brain-specifically expressed [74] and that mutations in PRKCG are associated with spinocerebellar ataxia [75, 76]. Additionally, it has been reported that PKC signaling pathways contribute to the aggressive behavior of glioma cells [77] and atypical PKC isozymes are fundamental regulators of tumorigenesis [78]. To our knowledge, several genes in $19 \mathrm{q}$ are closely associated with glioma (e.g., TTYH1(tweety family member 1), UBE2S (ubiquitin conjugating enzyme E2 S) $[79,80]$ ). However, the potential role of PRKCG in glioma remains unknown, and therefore, comprehensive molecular characterization of PRKCG across multi-omics glioma datasets is highly desirable.

\section{PRKCG is significantly differentially expressed among normal, LGG and GBM samples}

We first investigated the expression pattern of PRKCG among normal, LGG and GBM samples by using multiple discovery and validation datasets. We found that PRKCG expression is significantly reduced in gliomas by contrast to normal samples (Fig. 2a-f; $p$-value $<0.01$, Wilcoxon test). Furthermore, we discovered that PRKCG shows significantly different expression profiles among different anatomic regions (Fig. 2g; $p$-value $<0.01$, Wilcoxon test). Strikingly, PRKCG expression is highest in LE (the outermost boundary of the tumor), decreased in IT (the intermediate zone between the LE and the serious CT regions), and lowest in the serious regions (CT, PAN and MVP) (see details in Materials and Methods). Consistently, comparison between differentgrade gliomas showed that PRKCG expression is significantly lower in GBM samples than LGG samples (Fig. $2 \mathrm{~h}$-j; $p$-value $<0.01$, Wilcoxon test). We further investigated its expression across pan-cancer samples. Although it has been documented that PRKCG is upregulated in colon cancer [81], the up-regulation in colon cancer is extremely lower by comparison with glioma (LGG and GBM) (Additional file 5: Fig. S4). Taken together, these results presumably suggest that PRKCG is closely associated with glioma and its reduced expression is coupled with glioma progression (Fig. 2), highlighting its possible potential for glioma diagnosis.

\section{PRKCG expression is highly sensitive to survival}

PRKCG expression change from high to low is indicative of progression from normal to glioma and from LGG to GBM (Fig. 2), implying that PRKCG expression is significantly associated with glioma progression. Importantly, we observed that PRKCG expression is significantly associated with survival rate, which is testified by multiple 


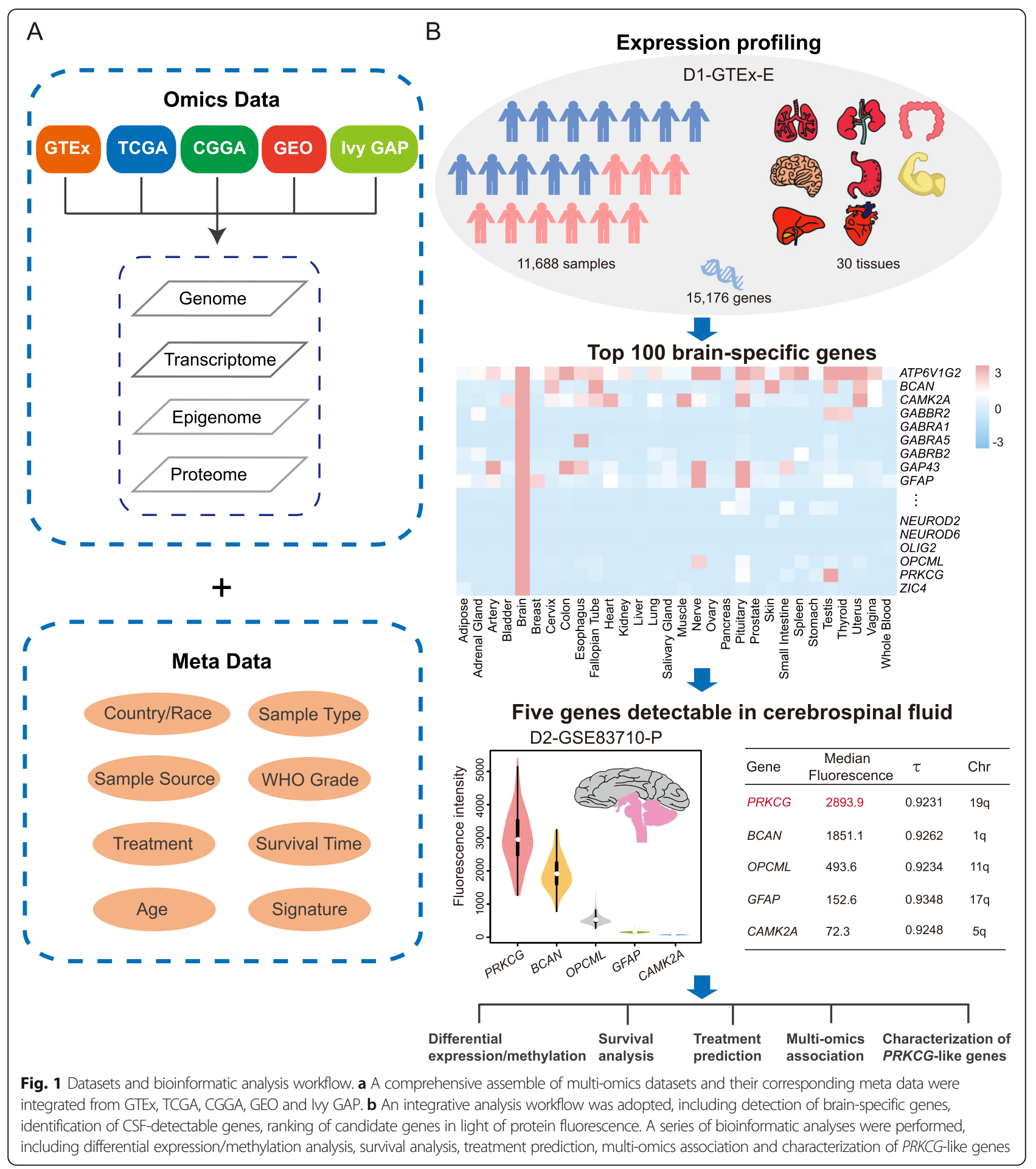

independent datasets (Fig. 3). Specifically, higher expression of PRKCG is indicative of longer overall survival in all glioma samples (Fig. 3a-b; $p$-value $<0.01$, log-rank test). When separating LGG samples from GBM samples, it is consistently observed that higher expression, albeit not statistically significant in all examined datasets, tends to have longer overall survival in both LGG and GBM samples (Fig. 3c-f). Obviously, PRKCG expression has the potential capability to differentiate samples with diverse survival states, which would be of critical significance for accurate glioma subtyping, better therapeutic decisions and precision healthcare. 

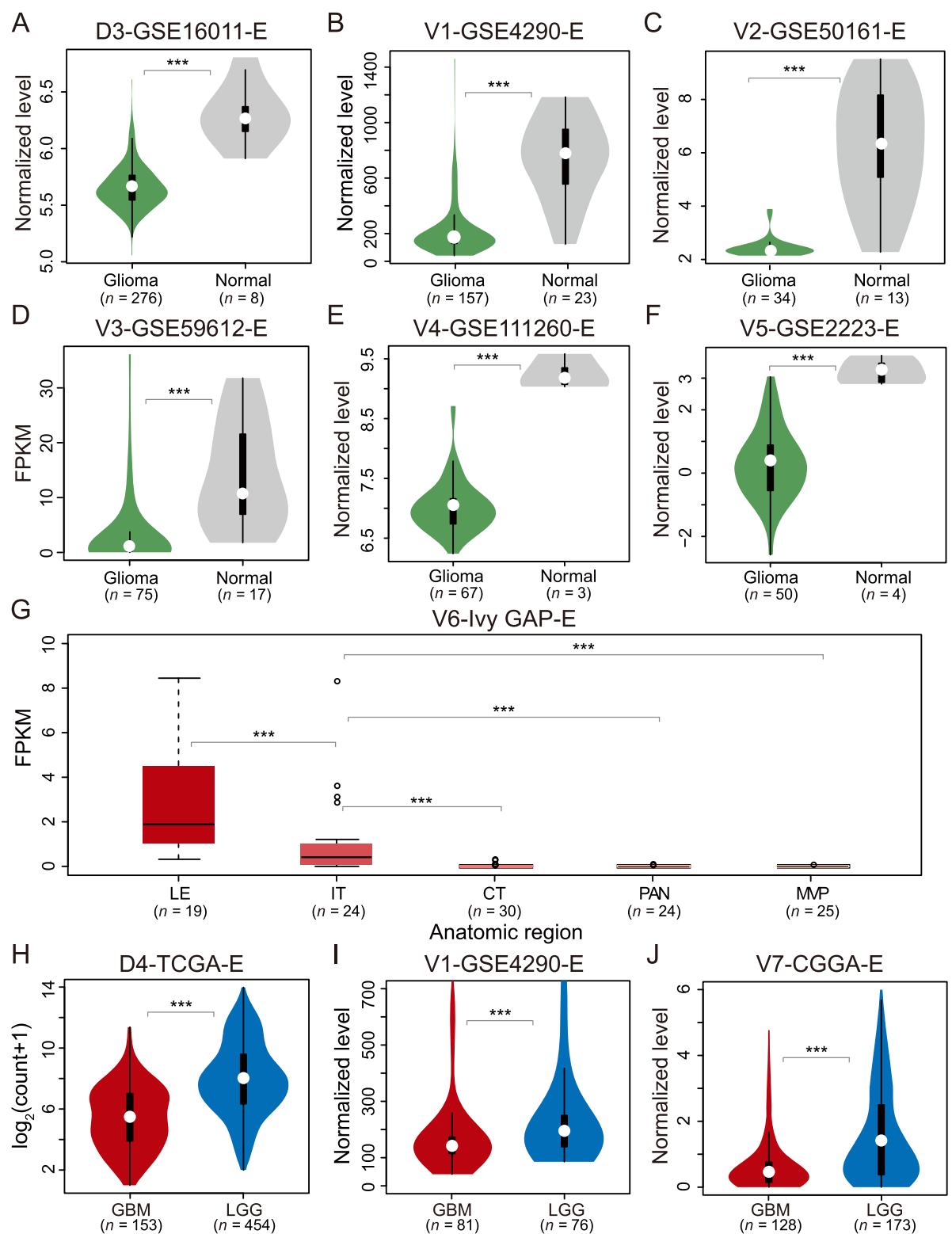

I A1-GSE4290-E
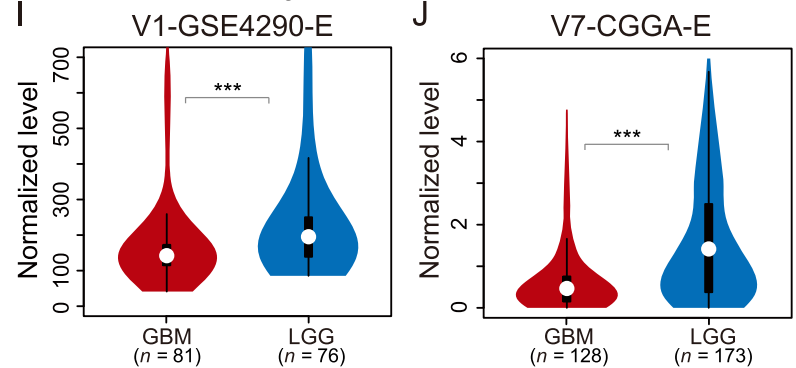

Fig. 2 Expression profiles of PRKCG across normal, LGG and GBM samples. PRKCG expression profiles were compared between glioma and normal samples (D3-GSE16011-E in panel a [RMA normalized], V1-GSE4290-E in panel b [MAS5 normalized], V2-GSE50161-E in panel c[gcRMA normalized], V3GSE59612-E in panel d, V4-GSE111260-E in panel e [RMA normalized], V5-GSE2223-E in panel $\mathbf{f}$ [Lowess normalized]), between different anatomic regions (V6-IVy GAP-E in panel g), and between GBM and LGG samples (D4-TCGA-E in panel $\mathbf{h}$, V1-GSE4290-E in panel i [MAS5 normalized] and V7CGGA-E in panel $\mathbf{j}$ [Lowess normalized]). All the normalization methods labeled above were derived from and detailed in their corresponding publications, and all these datasets were made publicly accessible at ftp://download.big.ac.cn/glioma_data/. The Wilcoxon tests were performed and the statistical significance levels were coded by: $n s p>0.05,{ }^{*} p<0.05,{ }^{* *} p<0.01$ and ${ }^{* * *} p<0.001$

\section{PRKCG is significantly differentially methylated among} normal, LGG and GBM samples

Since PRKCG harbors two CpG sites (namely, cg26626089 and cg04518808) that are located in the promoter region and covered in both HumanMethylation27 (27 K) and HumanMethylation450 (450 K) BeadChip datasets, we then systematically investigated DNA methylation profiles of these two sites among normal,
LGG and GBM samples. Apparently, the two sites show hypermethylation in GBM patients compared with normal samples (Fig. 4), which is more significant for cg26626089 (Fig. 4a and c; $p$-value <0.01, Wilcoxon test). Furthermore, we examined the variation of methylation level by using whole-genome bisulfite sequencing data of six GBM samples from TCGA and one normal sample from UCSC (2017 version; http://genome.ucsc. 

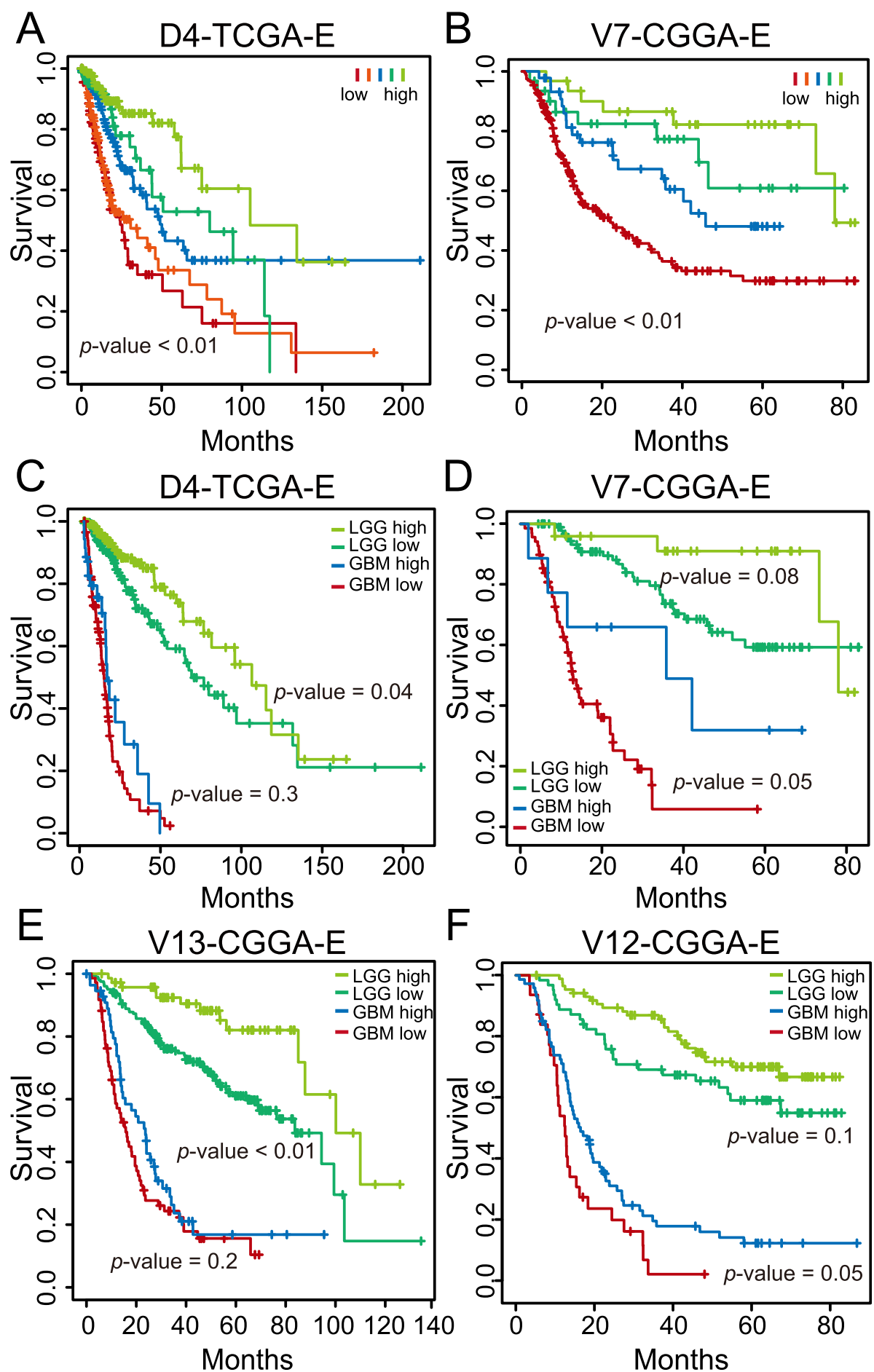

Fig. 3 Expression profiles of PRKCG associated with survival. Glioma samples were divided into different groups based on PRKCG expression (panels a and $\mathbf{b}$ ). LGG and GBM samples were divided into two groups with high expression and low expression, respectively (panels $\mathbf{c}$ to $\mathbf{f}$ ). All these datasets can be publicly accessible at ftp://download.big.ac.cn/glioma_data/. The log-rank tests were used to examine the statistical significance between different survival curves

edu, last accessed on 12 May 2019). Consistently, most GBM patients show higher methylation levels than normal samples (Additional file 6: Fig. S5). In addition, considering different-grade gliomas, both sites present much lower methylation levels in GBM samples than LGG samples (Fig. 4e-h; $p$-value $<0.01$, Wilcoxon test). 

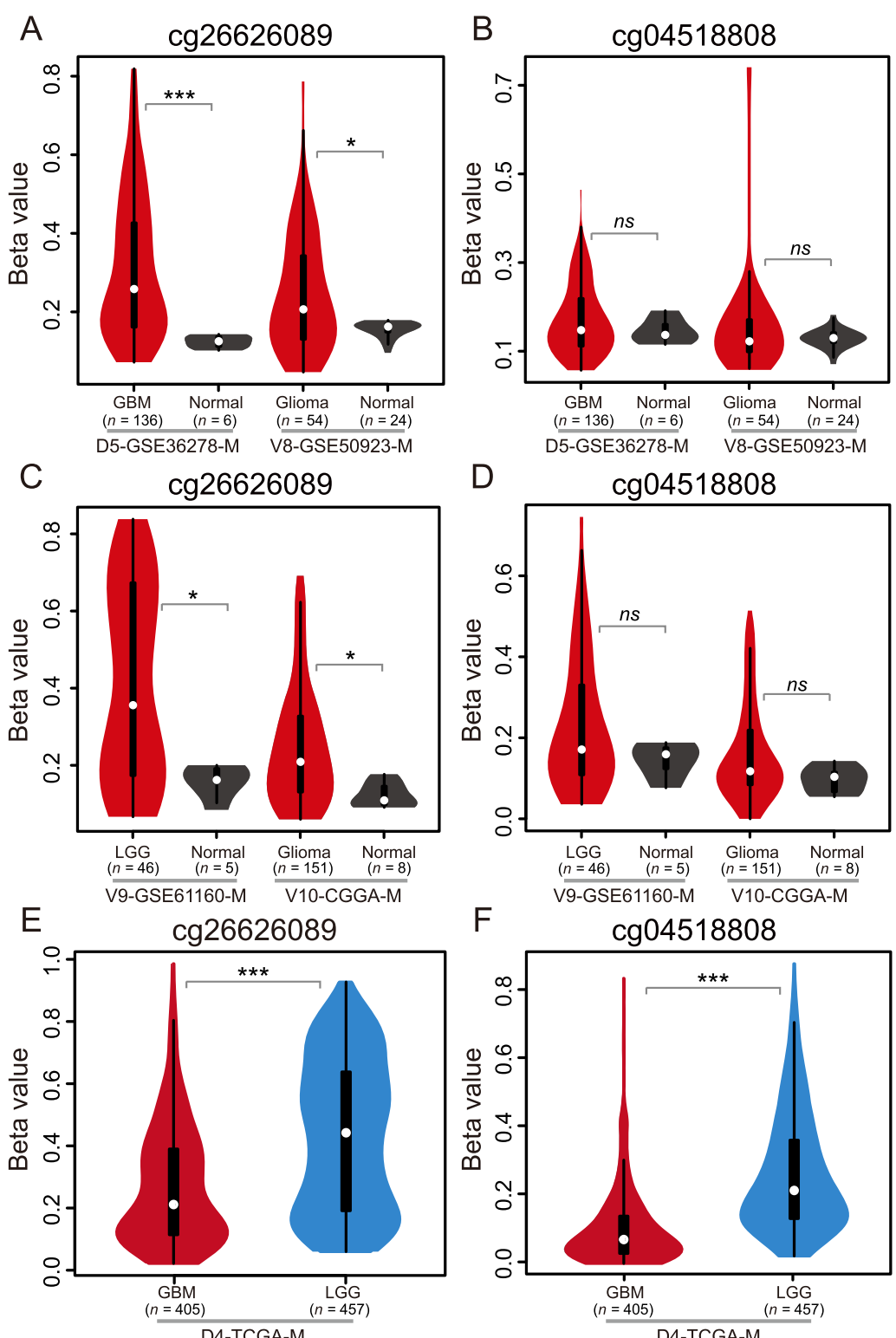

F
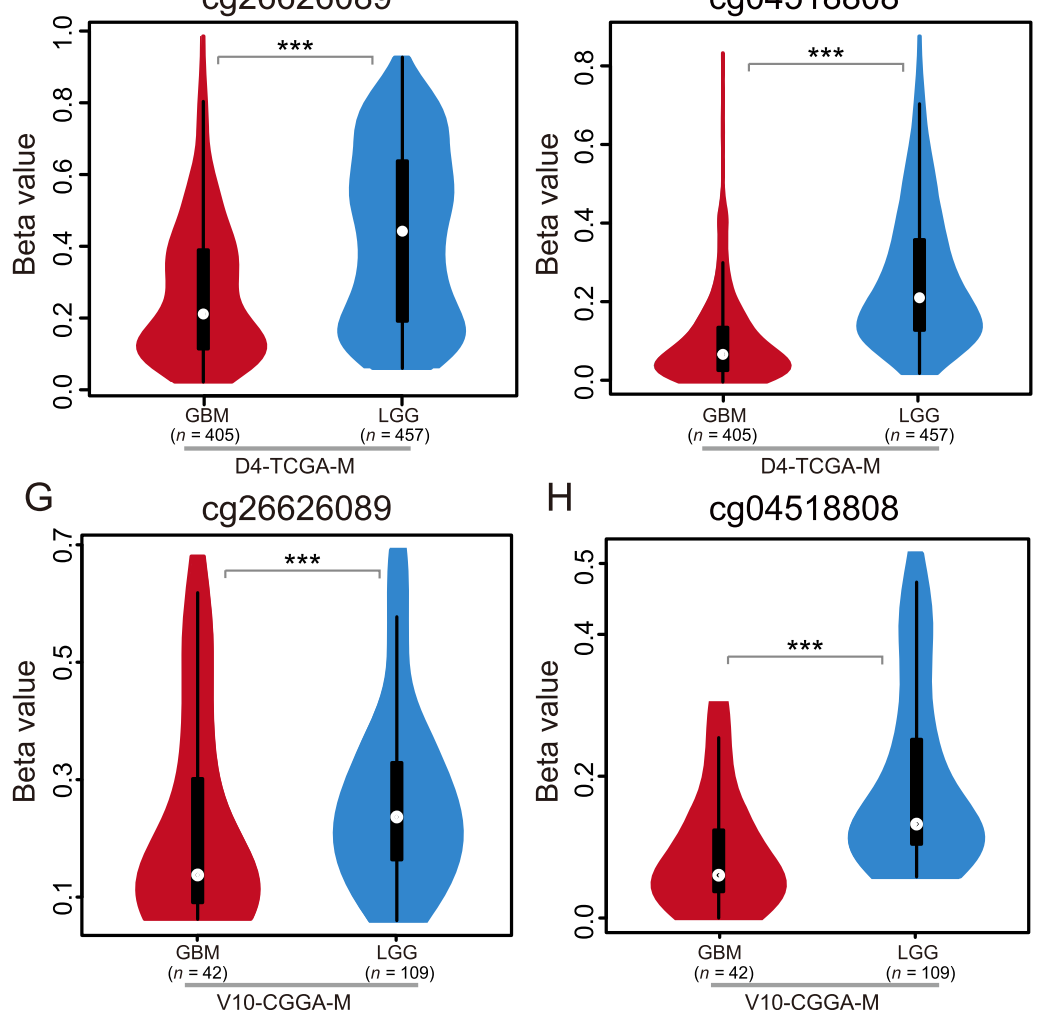

Fig. 4 (See legend on next page.) 
(See figure on previous page.)

Fig. 4 DNA methylation profiles across normal, LGG and GBM samples. PRKCG methylation profiles were compared between GBM and normal samples (panels a to $\mathbf{d}$ ), and between LGG and GBM samples (panels e to $\mathbf{h}$ ). All these datasets can be publicly accessible at ftp://download.big. ac.cn/glioma_data/. The Wilcoxon tests were used and their statistical significance levels were coded by: $n s p>0.05,{ }^{*} p<0.05,{ }^{*} p<0.01$ and *** $p<0.001$

We further investigated its methylation in pGBM and rGBM and obtained contradictory results in different populations; PRKCG methylation shows no significant difference in the Chinese population (V10-CGGA-M) (Additional file 7: Fig. S6A-B; $p$-value $>0.05$, Wilcoxon test) but significantly difference in the Switzerland population (V14-GSE60274-M) [55] (Additional file 7: Fig. S6C$\mathrm{D} ; p$-value $<0.05$, Wilcoxon test). This is most likely caused by the population genetic difference and/or the small sample size (both datasets have $<5$ rGBM samples).

Collectively, PRKCG is significantly differentially expressed/methylated among normal, LGG and GBM samples. Compared with normal samples, PRKCG presents lower expression and higher methylation in glioma samples. With tumor malignancy, PRKCG methylation and expression are both on the decrease (discussed below).

\section{Combined methylation signatures of PRKCG and MGMT are more effective in treatment prediction}

It is known that MGMT encodes a DNA-repair protein and hypermethylation of MGMT is associated with diminished DNA-repair activity, accordingly allowing the alkylating drug temozolomide (TMZ) to have greater effect in GBM treatment $[82,83]$. In our study, we obtained consistent results that patients with methylated MGMT are more sensitive to TMZ treatment than those with unmethylated MGMT (Fig. 5a; $p$-value $<0.01$, logrank test).

Considering that a single molecular biomarker might be lack of sufficient prediction power and thus fail to determine the clinical therapeutic efficacy due to tumor heterogeneity [84], we sought to examine the predictive potential of PRKCG for TMZ using 228 GBM samples with matched DNA methylation and clinical data. We

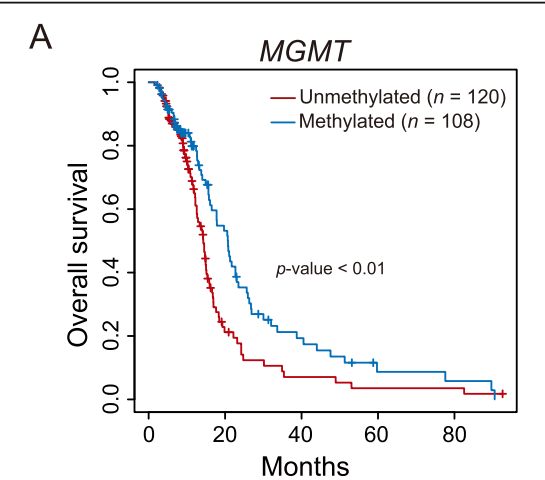

B

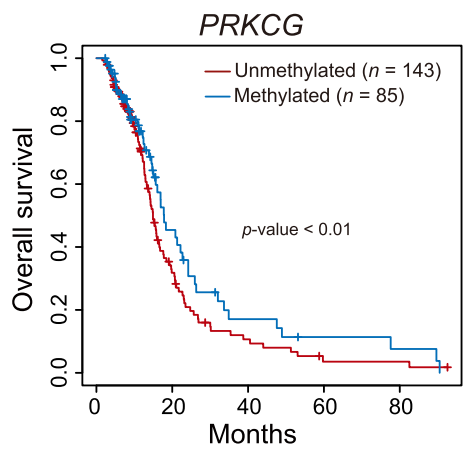

C

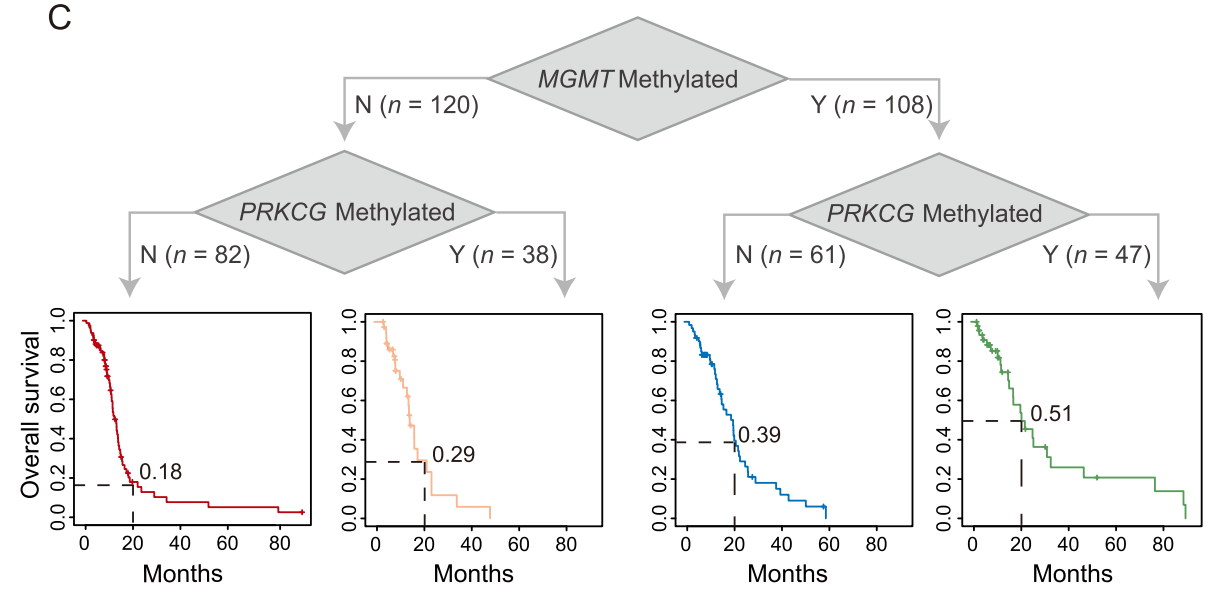

Fig. 5 Combined DNA methylation signatures of MGMT and PRKCG for treatment prediction. a Kaplan-Meier survival curves for GBM patients with TMZ treatment based on MGMT methylation. b Kaplan-Meier survival curves for GBM patients with TMZ treatment based on PRKCG (cg26626089) methylation. c Kaplan-Meier survival curves for GBM patients with TMZ treatment based on MGMT and PRKCG combined methylation signatures 
discovered that among the two CpG sites of PRKCG (cg26626089 and cg04518808), cg26626089 is able to classify patients into two groups with distinct survival advantages, as patients with methylated cg26626089 have significantly longer survival than those with unmethylated cg26626089 (Fig. 5b and Additional file 8: Fig. S7A). By combining PRKCG (cg26626089) with $M G M T$, intriguingly, GBM patients receiving TMZ treatment can be classified into four groups that exhibit significantly different survivals (Fig. $5 \mathrm{c}$ and Additional file 8: Fig. S7B; $p$-value $<0.01$, log-rank test). The four groups, namely, MGMT-unmethylated + PRKCGunmethylated, MGMT-unmethylated + PRKCG-methylated, MGMT-methylated + PRKCG-unmethylated, and MGMT-methylated + PRKCG-methylated, present gradually improved longer survivals, as their 20-month OS rates are $0.18,0.29,0.39$ and 0.51 (Fig. 5c), respectively, implying that the combined methylation signatures of PRKCG and MGMT might guide more accurate GBM stratification and achieve better personalized therapeutic decisions. Noticeably, elevated MGMT expression is associated with TMZ resistance [33]. Similarly, we consistently detected that the both-methylated group with better survival shows significantly lower expression of $M G M T$ (Additional file 8: Fig. S7C).

\section{Multi-omics molecular profiles of $P R K C G$}

Based on multi-omics profiles of PRKCG, we explored the relationship between $P R K C G$ and classical molecular features/glioma grades. First, PRKCG is located on the chromosome 19q13.42, unifying previous findings that $1 \mathrm{p} / 19 \mathrm{q}$ codel is closely associated with glioma. Consistently, PRKCG CNV is closely associated with 19q status (Additional file 9: Fig. S8A and Additional file 10: Fig. S9). Second, PRKCG methylation (cg26626089) is associated with $I D H$ status, agreeing well with the finding that $I D H$-mut is an initiating event that remodels the glioma methylome, resulting in extensive DNA hypermethylation $[12,85]$ and thus most likely indicating that PRKCG methylation is a passenger of $I D H$-mut status. As LGG samples are always associated with $I D H$-mut and GBM samples are associated with $I D H$-WT, it is not difficult to understand why the methylation level of PRKCG is significantly lower in GBM than in LGG (Fig. 4e-h). At the same time, such higher expression level and higher methylation level lead to the suspicion whether PRKCG expression in glioma is positively regulated by its DNA methylation or is attributable to its CNV.

As expected, when considering CNV loss and gain separately, PRKCG CNV is positively correlated with its expression, as observed in the $\mathrm{CNV}$ loss and gain groups, respectively (Additional file 9: Fig. S8B-C; $p$ value $<0.01$, Spearman correlation $=0.26 / 0.32$ ). However, such positive correlation is absent when ignoring the difference of CNV status (Additional file 9: Fig. S8D). According to the dosage effect theory [86], the CNV loss group should not express more PRKCG than the CNV gain group. This implies that there is probably another factor rather than $\mathrm{CNV}$ to dominantly regulate PRKCG expression in glioma. Although it contradicts the commonly accepted negative association between gene expression and promoter $\mathrm{CpG}$ methylation, a large-scale pan-cancer analysis has also revealed a positive correlation between promoter $\mathrm{CpG}$ methylation and gene expression [87]. Consistently, we did observe significant positive correlations between PRKCG expression and $\mathrm{CpG}$ methylation within the promoter region (Additional file 9: Fig. S8E-F). This positive regulation of $\mathrm{CpG}$ methylation is quite strong, which significantly improves PRKCG expression in LGG samples; even these samples exhibit obvious CNV loss (Additional file 9: Fig. S8A). Thus, it is presumably suggested that PRKCG is most likely regulated in different ways by DNA methylation, which negatively regulates $P R K C G$ expression from normal to tumor but positively regulates the expression within tumor. However, gene expression regulation is a more complicated process involving multiple factors aside from DNA methylation and CNV and more efforts on comprehensive and in-depth molecular characterization of glioma are highly needed to elucidate glioma pathogenesis.

\section{PRKCG-like genes may present heterogeneous roles in glioma tumorigenesis}

To better understand the regulation pattern of PRKCG, we further identified a total of 542 PRKCG-like genes that possess expression and DNA methylation patterns similar with PRKCG (see Materials and Methods) and investigated whether these genes present heterogeneous roles in glioma tumorigenesis (Fig. 6a-b and Additional file 1: Table S3). Noticeably, some of these PRKCG-like genes have already been reported to be closely related with glioma [88-92]. For instance, AKAP6 (A-kinase anchoring protein 6) polymorphisms are associated with glioma susceptibility and prognosis [91]; Phosphorylated SATB1 (SATB homeobox 1) contributes to the invasive and proliferative of GBM cells and is associated with glioma prognosis [88]; Higher expression of $C D K 17$ (cyclin dependent kinase 17) is indicative of longer overall survival [89]; PTPRM (protein tyrosine phosphatase receptor type $M$ ) expression is significantly reduced in GBM by contrast to LGG and higher expression is indicative of longer overall survival [90]; and CHD5 (chromodomain helicase DNA binding protein 5) might act as a tumor suppressor and its lower expression is associated with poor prognosis in glioma [92]. Among these PRKCG-like genes, we revealed that 114 genes show negative correlations between methylation level and expression level, whereas 297 genes present positive correlations (Additional file 1: Table 

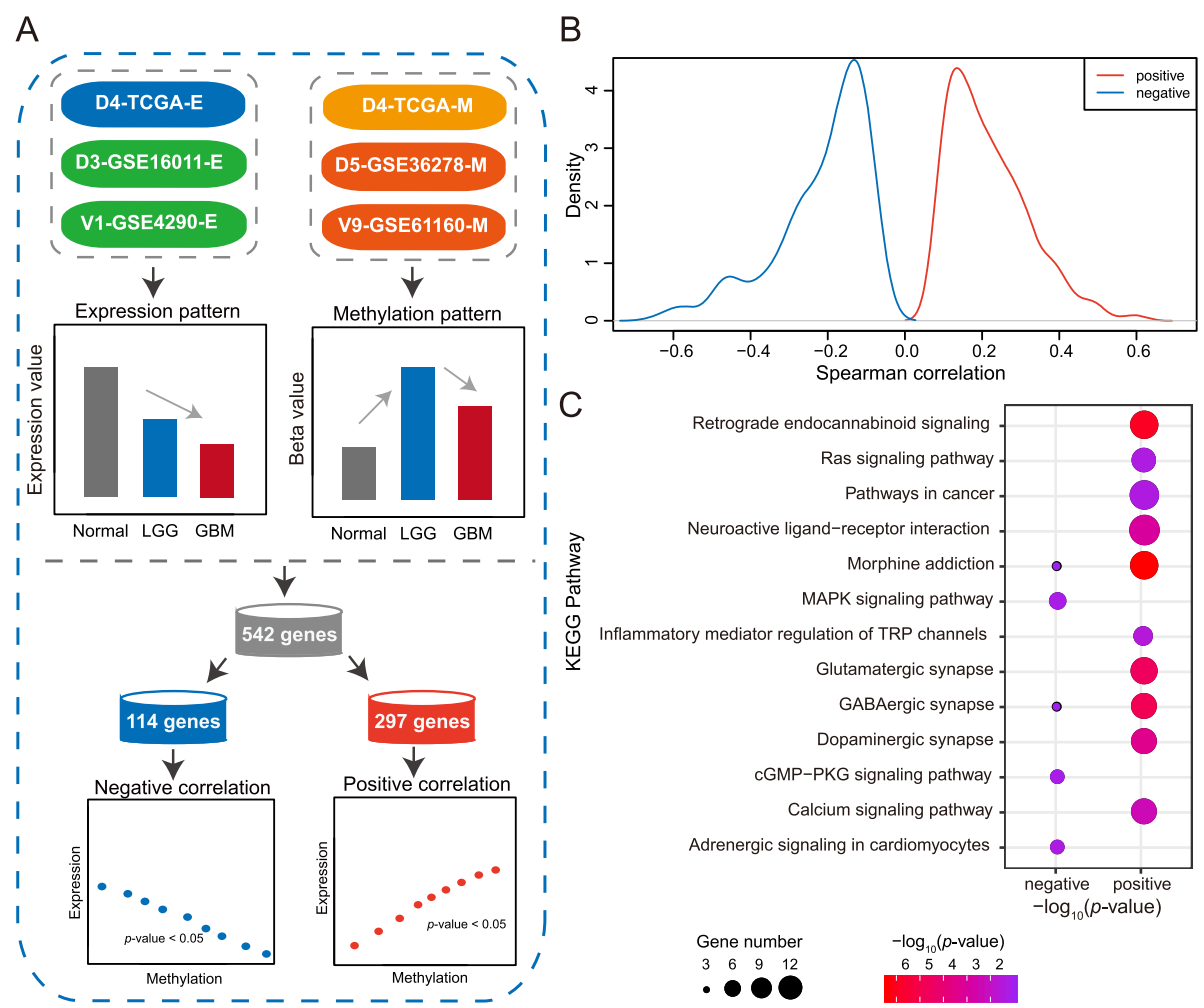

Fig. $\mathbf{6}$ Identification and characterization of PRKCG-like genes. a Identification of PRKCG-like genes, including two types of genes that possess negative and positive correlations between expression and DNA methylation, respectively. $\mathbf{b}$ Spearman correlations of two types of PRKCG-like genes. c The KEGG pathway enrichment of two types of PRKCG-like genes

S3). We further performed gene set enrichment analysis for these two groups' genes. We found that the negativelycorrelated genes are primarily enriched in the MAPK and cGMP-PKG signaling pathways, which are essential for tumor cell proliferation and differentiation [93, 94]. On the contrary, the positively-correlated genes are significantly involved in pathways relevant to cancer, inflammation and nerve synapse (Fig. 6c). Thus, PRKCG-like genes, presumably present heterogeneous roles in glioma tumorigenesis with complex molecular mechanisms that need further extensive explorations both bioinformatically and experimentally.

\section{Conclusion}

The rapid advancement of sequencing technologies enables large amounts of glioma data generated from different projects and studies throughout the world. Therefore, it has become crucially significant on how to make full use of these valuable data for computational identification and characterization of glioma candidate biomarkers. In this study, we, for the first time, assembled the most comprehensive collection of public glioma datasets with multi-omics data types and different populations/countries. Through comprehensive molecular profiling, we identified that PRKCG, a brain-specific gene detectable in CSF, is a potential biomarker for glioma diagnosis, prognosis and treatment prediction. Specifically, it presents lower expression and higher methylation in glioma samples than normal samples. PRKCG expression/methylation change from high to low is indicative of glioma progression from low-grade to high-grade and high RNA expression is suggestive of good survival. Importantly, PRKCG in combination with $M G M T$ is more effective to yield precise survival outcomes after TMZ chemotherapy. In harmony with classical biomarkers, PRKCG as well as PRKCG-like genes may play important and heterogeneous roles in glioma tumorigenesis. In the era of big data, our findings highlight the importance of computational integrative multiomics profiling and represent a data-driven scheme toward precision tumor subtyping, accurate therapeutic decisions and better personalized healthcare.

\section{Supplementary information}

Supplementary information accompanies this paper at https://doi.org/10. 1186/s13062-020-00264-5.

Additional file 1: Table S1. 15,176 genes' RNA expression levels across 30 normal human tissues. Table S2. Tissue specificity T values and 
maximum expression levels of the top 100 brain-specific protein-coding genes. Table S3. PRKCG-like genes and their annotations.

Additional file 2: Figure S1. Protein level distributions in CSF and RNA expression profiles of PRKCG (A), BCAN (B), OPCML (C), GFAP (D), CAMK2A (E) across 30 normal human tissues.

Additional file 3: Figure S2. Expression profiles of PRKCG (A), BCAN (B), OPCML (C), GFAP (D), and CAMK2A (E) across 13 human brain regions.

Additional file 4: Figure S3. Expression profiles of PRKCG in brain developmental stages.

Additional file 5: Figure S4. Expression profiles of PRKCG across 31 human tumor and normal tissues.

Additional file 6: Figure S5. Bisulfite DNA methylation profiles of PRKCG across six GBM samples and one normal sample.

Additional file 7: Figure S6. DNA methylation profiles of PRKCG in recurrent GBM (rGBM) and primary GBM (pGBM) samples. PRKCG methylation profiles were compared between rGBM and pGBM samples (V10-CGGA-M in panels A and B and V14-GSE60274-M in panels C and D). All these datasets can be publicly accessible at ftp://download.big.ac.cn/ glioma_data/. The Wilcoxon tests were used and the statistical significance levels were coded by: $n s p>0.05,{ }^{*} p<0.05,{ }^{* *} p<0.01$ and ${ }^{* * *}$ $p<0.001$.

Additional file 8: Figure S7. Predictive potential of PRKCG DNA methylation. (A) Kaplan-Meier survival curves for GBM patients with TMZ treatment based on PRKCG (cg04518808) methylation. (B) Methylation site cg26626089 in combination with MGMT, which were used to classify GBM patients into four groups. (C) Expression profiles of MGMT in the four groups.

Additional file 9: Figure S8. Multi-omics molecular profiles of PRKCG (A) Association of PRKCG's multi-omics signatures with IDH, 1p/19q status and WHO grade. (B) Correlation between PRKCG expression and CNV Loss. (C) Correlation between PRKCG expression and CNV Gain. (D) Correlation between PRKCG expression and all CNV status. (E) Correlation between PRKCG expression and DNA methylation of the CpG site cg04518808. (F) Correlation between PRKCG expression and DNA methylation of the CpG site cg26626089.

Additional file 10: Figure S9. PRKCG CNV associated with survival. (A) Four groups of glioma samples were divided based on the $1 \mathrm{p} / 19 \mathrm{q}$ status (19q gain, 19q normal, 1p/19q non-codel, and 1p/19q codel). (B) KaplanMeier survival probability, age, WHO grade and histology of the four groups.

\section{Abbreviations}

CNS: Central nervous system; IDH-mut: IDH mutation; IDH-WT: IDH wild-type; WHO: World Health Organization; CSF: Cerebrospinal fluid; TPM: Transcripts Per Million; pGBM: primary GBM; rGBM: recurrent GBM; IT: Infiltrating tumor; CT: Cellular tumor; PAN: Pseudo-palisading cells around necrosis; MVP: Microvascular proliferation; PKC: Protein kinase C; 27 K: HumanMethylation27; 450 K: HumanMethylation450; TMZ: Temozolomide

\section{Acknowledgements}

We thank Jun Yu, Songnian Hu, Fangqing Zhao, Yu Xue, Zheng Zhao, Jiabao Cao, Jian Sang, Guangyi Niu, Man Li, and Yang Zhang for their valuable comments and discussions on this work.

\section{Authors' contributions}

Conceptualization, LL and WGY; Methodology, LL, WGY, and ZZ; Validation, $\mathrm{LL}$ and WLG; Formal Analysis, LL, WGY, WLG, YCL and LMW; Investigation, LL and WGY; Writing - Original Draft, LL; Writing - Review \& Editing, MLN, WLG, SSH, HLL, and ZZ; Funding Acquisition, MLN and ZZ; Supervision, MLN and ZZ. The authors read and approved the final manuscript.

\section{Funding}

This work was supported by grants from The Strategic Priority Research Program of the Chinese Academy of Sciences [XDA19050302, XDB13040500], National Key Research \& Development Program of China [2017YFC0907502, 2015AA020108], National Natural Science Foundation of China [31871328], 13th Five-year Informatization Plan of Chinese Academy of Sciences
[XXH13505-05], K. C. Wong Education Foundation to Z.Z., the Youth Innovation Promotion Association of Chinese Academy of Sciences [2019104] to M.L.N., and International Partnership Program of the Chinese Academy of Sciences [153F11KYSB20160008].

\section{Availability of data and materials}

All datasets integrated in this study were obtained from multiple public database resources (see details in Table 1), which are freely available at ftp:// download.big.ac.cn/glioma_data/.

Ethics approval and consent to participate

Not applicable.

\section{Consent for publication}

All participants have read and approved for the manuscript.

\section{Competing interests}

The authors declare no competing interests.

\section{Author details}

${ }^{1}$ China National Center for Bioinformation, Beijing 100101, China. ${ }^{2}$ National Genomics Data Center \& CAS Key Laboratory of Genome Sciences and Information, Beijing Institute of Genomics, Chinese Academy of Sciences, Beijing 100101, China. ${ }^{3}$ University of Chinese Academy of Sciences, Beijing 100101, China. ${ }^{4}$ Present Address: The Methodist Hospital Research Institute, 6670 Bertner Ave, Houston, TX 77030, USA. ${ }^{5}$ Division of Biomedical Statistics and Informatics, Mayo Clinic College of Medicine, Rochester, MN 55905, USA.

Received: 14 February 2020 Accepted: 4 June 2020

Published online: 15 June 2020

\section{References}

1. Schwartzbaum JA, Fisher JL, Aldape KD, Wrensch M. Epidemiology and molecular pathology of glioma. Nat Clin Pract Neurol. 2006;2(9):494-503 quiz 491 p following 516.

2. Maher EA, Furnari FB, Bachoo RM, Rowitch DH, Louis DN, Cavenee WK, DePinho RA. Malignant glioma: genetics and biology of a grave matter. Genes Dev. 2001;15(11):1311-33.

3. Stewart LA. Chemotherapy in adult high-grade glioma: a systematic review and meta-analysis of individual patient data from 12 randomised trials. Lancet. 2002:359(9311):1011-8.

4. Louis DN, Ohgaki H, Wiestler OD, Cavenee WK, Burger PC, Jouvet A, Scheithauer BW, Kleihues P. The 2007 WHO classification of tumours of the central nervous system. Acta Neuropathol. 2007;114(2):97-109.

5. Wesseling P, Kros JM, Jeuken JWM. The pathological diagnosis of diffuse gliomas: towards a smart synthesis of microscopic and molecular information in a multidisciplinary context. Diagnos Histopathol. 2011:17(11): 486-94

6. Kim YW, Koul D, Kim SH, Lucio-Eterovic AK, Freire PR, Yao J, Wang J, Almeida JS, Aldape K, Yung WK. Identification of prognostic gene signatures of glioblastoma: a study based on TCGA data analysis. Neuro Oncol. 2013; 15(7):829-39.

7. Wiestler B, Capper D, Holland-Letz T, Korshunov A, von Deimling A, Pfister SM, Platten M, Weller M, Wick W. ATRX loss refines the classification of anaplastic gliomas and identifies a subgroup of IDH mutant astrocytic tumors with better prognosis. Acta Neuropathol. 2013;126(3):443-51.

8. Cohen AL, Holmen SL, Colman H. IDH1 and IDH2 mutations in gliomas. Curr Neurol Neurosci Rep. 2013:13(5):345.

9. Eckel-Passow JE, Lachance DH, Molinaro AM, Walsh KM, Decker PA, Sicotte H, Pekmezci M, Rice T, Kosel ML, Smirnov IV, et al. Glioma groups based on 1p/19q, IDH, and TERT promoter mutations in tumors. N Engl J Med. 2015; 372(26):2499-508

10. Waitkus MS, Diplas BH, Yan H. Biological role and therapeutic potential of IDH mutations in Cancer. Cancer Cell. 2018;34(2):186-95.

11. Kloosterhof NK, Bralten LBC, Dubbink HJ, French PJ, van den Bent MJ. Isocitrate dehydrogenase-1 mutations: a fundamentally new understanding of diffuse glioma? Lancet Oncol. 2011;12(1):83-91.

12. Turcan S, Rohle D, Goenka A, Walsh LA, Fang F, Yilmaz E, Campos C, Fabius AW, Lu C, Ward PS, et al. IDH1 mutation is sufficient to establish the glioma hypermethylator phenotype. Nature. 2012;483(7390):479-83. 
13. Jenkins RB, Blair H, Ballman KV, Giannini C, Arusell RM, Law M, Flynn H, Passe S, Felten S, Brown PD, et al. A t(1;19)(q10;p10) mediates the combined deletions of $1 p$ and $19 q$ and predicts a better prognosis of patients with oligodendroglioma. Cancer Res. 2006;66(20):9852-61.

14. Cairncross G, Wang M, Shaw E, Jenkins R, Brachman D, Buckner J, Fink K, Souhami L, Laperriere N, Curran W, et al. Phase III trial of chemoradiotherapy for anaplastic oligodendroglioma: long-term results of RTOG 9402. J Clin Oncol. 2013;31(3):337-43.

15. Mur P, Mollejo M, Hernandez-Iglesias T, de Lope AR, Castresana JS, Garcia JF, Fiano C, Ribalta T, Rey JA, Melendez B. Molecular classification defines 4 prognostically distinct glioma groups irrespective of diagnosis and grade. Neuropathol Exp Neurol. 2015;74(3):241-9.

16. Molinaro AM, Taylor JW, Wiencke JK, Wrensch MR. Genetic and molecular epidemiology of adult diffuse glioma. Nat Rev Neurol. 2019;15(7):405-17.

17. Louis DN, Perry A, Reifenberger G, von Deimling A, Figarella-Branger D, Cavenee WK, Ohgaki H, Wiestler OD, Kleihues P, Ellison DW. The 2016 World Health Organization classification of tumors of the central nervous system: a summary. Acta Neuropathol. 2016;131(6):803-20.

18. Flynn JR, Wang L, Gillespie DL, Stoddard GJ, Reid JK, Owens J, Ellsworth GB, Salzman KL, Kinney AY, Jensen RL. Hypoxia-regulated protein expression, patient characteristics, and preoperative imaging as predictors of survival in adults with glioblastoma multiforme. Cancer. 2008;113(5):1032-42.

19. Verhaak RGW, Hoadley KA, Purdom E, Wang V, Qi Y, Wilkerson MD, Miller CR, Ding L, Golub T, Mesirov JP, et al. Integrated genomic analysis identifies clinically relevant subtypes of Glioblastoma characterized by abnormalities in PDGFRA, IDH1, EGFR, and NF1. Cancer Cell. 2010;17(1):98-110.

20. Wang Q, Hu B, Hu X, Kim H, Squatrito M, Scarpace L, de Carvalho AC, Lyu S, Li P. Tumor evolution of glioma intrinsic gene expression subtype associates with immunological changes in the microenvironment. Cancer Cell. 2017; 32(1):42-56.

21. Gao W-Z, Guo L-M, Xu T-Q, Yin Y-H, Jia F. Identification of a multidimensional transcriptome signature for survival prediction of postoperative glioblastoma multiforme patients. J Transl Med. 2018;16(1): 368.

22. Hatanpaa KJ, Burma S, Zhao D, Habib AA. Epidermal growth factor receptor in glioma: signal transduction, neuropathology, imaging, and radioresistance. Neoplasia. 2010;12(9):675-84.

23. Gan HK, Kaye AH, Luwor RB. The EGFRvIll variant in glioblastoma multiforme. J Clin Neurosci. 2009;16(6):748-54.

24. Mukherjee B, McEllin B, Camacho CV, Tomimatsu N, Sirasanagandala S, Nannepaga S, Hatanpaa KJ, Mickey B, Madden C, Maher E, et al. EGFRvIII and DNA double-Strand break repair: a molecular mechanism for Radioresistance in Glioblastoma. Cancer Res. 2009;69(10):4252-9.

25. Zhang S, Zhao BS, Zhou A, Lin K, Zheng S, Lu Z, Chen Y, Sulman EP, Xie K, Bogler O, et al. m(6) A Demethylase ALKBH5 maintains Tumorigenicity of Glioblastoma stem-like cells by sustaining FOXM1 expression and cell proliferation program. Cancer Cell. 2017;31(4):591-606 e596

26. Esteller M. Cancer epigenomics: DNA methylomes and histone-modification maps. Nat Rev Genet. 2007:8(4):286-98.

27. Park JY, Lee JE, Park JB, Yoo H, Lee SH, Kim JH. Roles of Long non-coding RNAs on tumorigenesis and Glioma development. Brain Tumor Res Treat. 2014;2(1):1-6.

28. Zang L, Kondengaden SM, Che F, Wang L, Heng X. Potential epigeneticbased therapeutic targets for Glioma. Front Mol Neurosci. 2018;11:408.

29. Malzkorn B, Wolter M, Riemenschneider MJ, Reifenberger G. Unraveling the Glioma Epigenome-from molecular mechanisms to novel biomarkers and therapeutic targets. Brain Pathol. 2011;21(6):619-32.

30. Binabaj MM, Bahrami A, ShahidSales S, Joodi M, Joudi Mashhad M, Hassanian SM, Anvari K, Avan A. The prognostic value of MGMT promoter methylation in glioblastoma: a meta-analysis of clinical trials. J Cell Physiol. 2018;233(1):378-86.

31. Wick W, Weller M, van den Bent M, Sanson M, Weiler M, von Deimling A, Plass C, Hegi M, Platten M, Reifenberger G. MGMT testing--the challenges for biomarker-based glioma treatment. Nat Rev Neurol. 2014;10(7):372-85.

32. Rivera AL, Pelloski CE, Gilbert MR, Colman H, De La Cruz C, Sulman EP, Bekele BN, Aldape KD. MGMT promoter methylation is predictive of response to radiotherapy and prognostic in the absence of adjuvant alkylating chemotherapy for glioblastoma. Neuro Oncol. 2010;12(2):116-21.

33. Hegi ME, Diserens AC, Gorlia T, Hamou MF, de Tribolet N, Weller M, Kros JM, Hainfellner JA, Mason W, Mariani L, et al. MGMT gene silencing and benefit from temozolomide in glioblastoma. N Engl J Med. 2005;352(10):997-1003.
34. Cancer Genome Atlas Research N, Brat DJ, Verhaak RG, Aldape KD, Yung WK, Salama SR, Cooper LA, Rheinbay E, Miller CR, Vitucci M, et al. Comprehensive, integrative genomic analysis of diffuse lower-grade Gliomas. N Engl J Med. 2015:372(26):2481-98.

35. Ceccarelli M, Barthel FP, Malta TM, Sabedot TS, Salama SR, Murray BA, Morozova O, Newton Y, Radenbaugh A, Pagnotta SM, et al. Molecular profiling reveals biologically discrete subsets and pathways of progression in diffuse Glioma. Cell. 2016;164(3):550-63.

36. Zhao Z, Zhang K, Wang Z, Wang K, Liu X, Wu F, Chen J. A comprehensive review of available omics data resources and molecular profiling for precision glioma studies. Biomed Rep. 2019;10(1):3-9.

37. Cao H, Wang F, Li XJ. Future strategies on Glioma research: from big data to the clinic. Genomics Proteomics Bioinformatics. 2017;15(4):263-5.

38. Yang Y, Sui Y, Xie B, Qu H, Fang X. GliomaDB: a web server for integrating Glioma Omics data and interactive analysis. Genomics Proteomics Bioinformatics. 2019;17(4):465-71

39. Lonsdale J, Thomas J, Salvatore M, Phillips R, Lo E, Shad S, Hasz R, Walters G, Garcia F, Young N, Foster B. The genotype-tissue expression (GTEx) project. Nat Genet. 2013;45(6):580-5.

40. Puchalski RB, Shah N, Miller J, Dalley R, Nomura SR, Yoon J-G, Smith KA, Lankerovich M, Bertagnolli D, Bickley K, et al. An anatomic transcriptional atlas of human glioblastoma. Science. 2018;360(6389):660-3.

41. Bao ZS, Chen HM, Yang MY, Zhang CB, Yu K, Ye WL, Hu BQ, Yan W, Zhang W, Akers J, et al. RNA-seq of 272 gliomas revealed a novel, recurrent PTPRZ1-MET fusion transcript in secondary glioblastomas. Genome Res. 2014;24(11):1765-73.

42. Sun Y, Zhang W, Chen D, Lv Y, Zheng J, Lilljebjorn H, Ran L, Bao Z, Soneson C, Sjogren $\mathrm{HO}$, et al. A glioma classification scheme based on coexpression modules of EGFR and PDGFRA. Proc Natl Acad Sci U S A. 2014;111(9):3538-43.

43. Sasayama D, Hattori K, Ogawa S, Yokota Y, Matsumura R, Teraishi T, Hori H, Ota M, Yoshida S, Kunugi H. Genome-wide quantitative trait loci mapping of the human cerebrospinal fluid proteome. Hum Mol Genet. 2017;26(1):44-51.

44. Gravendeel LA, Kouwenhoven MC, Gevaert O, de Rooi JJ, Stubbs AP, Duijm JE, Daemen A, Bleeker FE, Bralten LB, Kloosterhof NK, et al. Intrinsic gene expression profiles of gliomas are a better predictor of survival than histology. Cancer Res. 2009;69(23):9065-72.

45. Sturm D, Witt H, Hovestadt V, Khuong-Quang DA, Jones DT, Konermann C, Pfaff $\mathrm{E}$, Tonjes M, Sill M, Bender S, et al. Hotspot mutations in H3F3A and IDH1 define distinct epigenetic and biological subgroups of glioblastoma. Cancer Cell. 2012;22(4):425-37.

46. Sun L, Hui AM, Su Q, Vortmeyer A, Kotliarov Y, Pastorino S, Passaniti A, Menon J, Walling J, Bailey R, et al. Neuronal and glioma-derived stem cell factor induces angiogenesis within the brain. Cancer Cell. 2006;9(4):287-300.

47. Griesinger AM, Birks DK, Donson AM, Amani V, Hoffman LM, Waziri A, Wang M, Handler MH, Foreman NK. Characterization of distinct immunophenotypes across pediatric brain tumor types. J Immunol. 2013; 191(9):4880-8.

48. Gill BJ, Pisapia DJ, Malone HR, Goldstein H, Lei L, Sonabend A, Yun J, Samanamud J, Sims JS, Banu M, et al. MRI-localized biopsies reveal subtypespecific differences in molecular and cellular composition at the margins of glioblastoma. Proc Natl Acad Sci U S A. 2014;111(34):12550-5.

49. Bredel M, Bredel C, Juric D, Harsh GR, Vogel H, Recht LD, Sikic BI. Functional network analysis reveals extended gliomagenesis pathway maps and three novel MYC-interacting genes in human gliomas. Cancer Res. 2005;65(19): 8679-89.

50. Bredel M, Bredel C, Juric D, Duran GE, Yu RX, Harsh GR, Vogel H, Recht LD, Scheck AC, Sikic BI. Tumor necrosis factor-alpha-induced protein 3 as a putative regulator of nuclear factor-kappaB-mediated resistance to O6alkylating agents in human glioblastomas. J Clin Oncol. 2006;24(2):274-87.

51. Yan W, Zhang W, You G, Zhang J, Han L, Bao Z, Wang Y, Liu Y, Jiang C, Kang $C$, et al. Molecular classification of gliomas based on whole genome gene expression: a systematic report of 225 samples from the Chinese Glioma cooperative group. Neuro Oncol. 2012;14(12):1432-40.

52. Lai RK, Chen Y, Guan X, Nousome D, Sharma C, Canoll P, Bruce J, Sloan AE, Cortes E, Vonsattel JP, et al. Genome-wide methylation analyses in glioblastoma multiforme. PLoS One. 2014;9(2):e89376.

53. Mur P, Mollejo M, Ruano Y, de Lope AR, Fiano C, Garcia JF, Castresana JS, Hernandez-Lain A, Rey JA, Melendez B. Codeletion of $1 p$ and $19 q$ determines distinct gene methylation and expression profiles in IDHmutated oligodendroglial tumors. Acta Neuropathol. 2013;126(2):277-89. 
54. Zhang W, Yan W, You G, Bao Z, Wang Y, Liu Y, You Y, Jiang T. Genomewide DNA methylation profiling identifies ALDH1A3 promoter methylation as a prognostic predictor in G-CIMP- primary glioblastoma. Cancer Lett. 2013;328(1):120-5.

55. Kurscheid S, Bady P, Sciuscio D, Samarzija I, Shay T, Vassallo I, Criekinge WV, Daniel RT, van den Bent MJ, Marosi C, et al. Chromosome 7 gain and DNA hypermethylation at the HOXA10 locus are associated with expression of a stem cell related HOX-signature in glioblastoma. Genome Biol. 2015;16:16.

56. Yanai I, Benjamin H, Shmoish M, Chalifa-Caspi V, Shklar M, Ophir R, Bar-Even A, Horn-Saban S, Safran M, Domany E, et al. Genome-wide midrange transcription profiles reveal expression level relationships in human tissue specification. Bioinformatics. 2005;21(5):650-9.

57. Klee EW. Data mining for biomarker development: a review of tissue specificity analysis. Clin Lab Med. 2008;28(1):127-43 viii.

58. Vasmatzis G, Klee EW, Kube DM, Therneau TM, Kosari F. Quantitating tissue specificity of human genes to facilitate biomarker discovery. Bioinformatics. 2007;23(11):1348-55

59. Kim P, Park A, Han G, Sun H, Jia P, Zhao Z. TissGDB: tissue-specific gene database in cancer. Nucleic Acids Res. 2018:46(D1):D1031-8.

60. Prassas L, Chrystoja CC, Makawita S, Diamandis EP. Bioinformatic identification of proteins with tissue-specific expression for biomarker discovery. BMC Med. 2012;10:39.

61. Mohammed A, Biegert G, Adamec J, Helikar T. Identification of potential tissue-specific cancer biomarkers and development of cancer versus normal genomic classifiers. Oncotarget. 2017;8(49):85692-715.

62. Gate D, Saligrama N, Leventhal O, Yang AC, Unger MS, Middeldorp J, Chen K, Lehallier B, Channappa D, De Los Santos MB, et al. Clonally expanded CD8 T cells patrol the cerebrospinal fluid in Alzheimer's disease. Nature. 2020;8:1-6.

63. Khasawneh AH, Garling RJ, Harris CA. Cerebrospinal fluid circulation: what do we know and how do we know it? Brain Circul. 2018:4:14.

64. Gary SC, Zerillo CA, Veronica L, Chiang VL, Gaw JU, Gray G, Hockfield S. CDNA cloning, chromosomal localization, and expression analysis of human $\mathrm{BEHAB/brevican,} \mathrm{a} \mathrm{brain} \mathrm{specific} \mathrm{proteoglycan} \mathrm{regulated} \mathrm{during} \mathrm{cortical}$ development and in glioma. Gene. 2000;256(1-2):139-47.

65. Phillips HS, Kharbanda S, Chen R, Forrest WF, Soriano RH, Wu TD, Misra A, Nigro JM, Colman H, Soroceanu L, et al. Molecular subclasses of high-grade glioma predict prognosis, delineate a pattern of disease progression, and resemble stages in neurogenesis. Cancer Cell. 2006;9(3):157-73.

66. Cook PJ, Thomas R, Kannan R, de Leon ES, Drilon A, Rosenblum MK, Scaltriti M, Benezra R, Ventura A. Author correction: somatic chromosomal engineering identifies BCAN-NTRK1 as a potent glioma driver and therapeutic target. Nat Commun. 2018;9:16187.

67. Reed JE, Dunn JR, du Plessis DG, Shaw EJ, Reeves P, Gee AL, Warnke PC, Sellar GC, Moss DJ, Walker C. Expression of cellular adhesion molecule 'OPCML' is down-regulated in gliomas and other brain tumours. Neuropathol Appl Neurobiol. 2007;33(1):77-85.

68. Carminati PO, Mello SS, Fachin AL, Junta CM, Sandrin-Garcia P, Carlotti CG, Donadi EA, Passos GA, Sakamoto-Hojo ET. Alterations in gene expression profiles correlated with cisplatin cytotoxicity in the glioma U343 cell line. Genet Mol Biol. 2010;33(1):159-68.

69. Horst M, Brouwer E, Verwijnen S, Rodijk M, de Jong M, Hoeben R, de Leeuw B, Smitt PS. Targeting malignant gliomas with a glial fibrillary acidic protein (GFAP)-selective oncolytic adenovirus. J Gene Med. 2007;9(12):1071-9.

70. van Bodegraven EJ, van Asperen JV, Robe PAJ, Hol EM. Importance of GFAP isoform-specific analyses in astrocytoma. Glia. 2019;67(8):1417-33.

71. John S, Sivakumar KC, Mishra R. Bacoside a induces tumor cell death in human Glioblastoma cell lines through catastrophic macropinocytosis. Front Mol Neurosci. 2017:10:171.

72. Long H, Liang C, Zhang X, Fang L, Wang G, Qi S, Huo H, Song Y. Prediction and analysis of key genes in Glioblastoma based on bioinformatics. Biomed Res Int. 2017:2017:7653101.

73. Shao Y, Chen C, Shen H, He BZ, Yu D, Jiang S, Zhao S, Gao Z, Zhu Z, Chen $X$, et al. GenTree, an integrated resource for analyzing the evolution and function of primate-specific coding genes. Genome Res. 2019;29(4):682-96.

74. Saito N, Shirai Y. Protein kinase C gamma (PKC gamma): function of neuron specific isotype. J Biochem. 2002;132(5):683-7.

75. Klebe S, Durr A, Rentschler A, Hahn-Barma V, Abele M, Bouslam N, Schols L, Jedynak P, Forlani $S$, Denis E, et al. New mutations in protein kinase Cgamma associated with spinocerebellar ataxia type 14. Ann Neurol. 2005; $58(5): 720-9$
76. Yabe I, Sasaki H, Chen DH, Raskind WH, Bird TD, Yamashita I, Tsuji S, Kikuchi S, Tashiro K. Spinocerebellar ataxia type 14 caused by a mutation in protein kinase C gamma. Arch Neurol. 2003;60(12):1749-51.

77. do Carmo A, Balca-Silva J, Matias D, Lopes MC. PKC signaling in glioblastoma. Cancer Biol Ther. 2013;14(4):287-94.

78. Reina-Campos M, Diaz-Meco MT, Moscat J. The dual roles of the atypical protein kinase Cs in Cancer. Cancer Cell. 2019;36(3):218-35.

79. Hu L, Li X, Liu Q, Xu J, Ge H, Wang Z, Wang H, Wang Z, Shi C, Xu X, et al. UBE2S, a novel substrate of Akt1, associates with Ku70 and regulates DNA repair and glioblastoma multiforme resistance to chemotherapy. Oncogene. 2017:36(8):1145-56.

80. Jung E, Osswald M, Blaes J, Wiestler B, Sahm F, Schmenger T, Solecki G, Deumelandt K, Kurz FT, Xie R, et al. Tweety-homolog 1 drives brain colonization of Gliomas. J Neurosci. 2017;37(29):6837-50.

81. Dowling CM, Hayes SL, Phelan JJ, Cathcart MC, Finn SP, Mehigan B, McCormick P, Coffey JC, O'sullivan J, Kiely PA. Expression of protein kinase C gamma promotes cell migration in colon cancer. Oncotarget. 2017;8(42): 72096-107.

82. Fukushima T, Takeshima H, Kataoka H. Anti-glioma therapy with temozolomide and status of the DNA-repair gene MGMT. Anticancer Res. 2009;29(11):4845-54

83. Stupp R, Mason WP, van den Bent MJ, Weller M, Fisher B, Taphoorn MJB, Belanger K, Brandes AA, Marosi C, Bogdahn U, et al. Radiotherapy plus concomitant and adjuvant Temozolomide for Glioblastoma. N Engl J Med. 2005;352(10):987-96

84. Li YH, Yu CY, Li XX, Zhang P, Tang J, Yang Q, Fu T, Zhang X, Cui X, Tu G, et al. Therapeutic target database update 2018: enriched resource for facilitating bench-to-clinic research of targeted therapeutics. Nucleic Acids Res. 2018:46(D1):D1121-7.

85. Noushmehr H, Weisenberger DJ, Diefes K, Phillips HS, Pujara K, Berman BP Pan F, Pelloski CE, Sulman EP, Bhat KP, et al. Identification of a $\mathrm{CpG}$ island methylator phenotype that defines a distinct subgroup of glioma. Cancer Cell. 2010;17(5):510-22.

86. Henrichsen CN, Chaignat E, Reymond A. Copy number variants, diseases and gene expression. Hum Mol Genet. 2009;18(R1):R1-8.

87. John CG, Spainhour HSL, Yi SV, Qiu P. Correlation patterns between DNA methylation and gene expression in the Cancer genome atlas. Cancer Informat. 2019;18:1176935119828776.

88. Han S, Xia J, Qin X, Han S, Wu A. Phosphorylated SATB1 is associated with the progression and prognosis of glioma. Cell Death Dis. 2013;4:e901.

89. Liu M, Xu Z, Du Z, Wu B, Jin T, Xu K, Xu L, Li E, Xu H. The identification of key genes and pathways in Glioma by bioinformatics analysis. J Immunol Res. 2017;2017:1278081.

90. Bourgonje AM, Verrijp K, Schepens JTG, Navis AC, Piepers JAF, Palmen CBC, van den Eijnden M, Hooft van Huijsduijnen R, Wesseling P, Leenders WPJ, et al. Comprehensive protein tyrosine phosphatase mRNA profiling identifies new regulators in the progression of glioma. Acta Neuropathologica Communications. 2016;4(1):96.

91. Zhang M, Zhao Y, Zhao J, Huang T, Wu Y. Impact of AKAP6 polymorphisms on Glioma susceptibility and prognosis. BMC Neurol. 2019;19(1):296.

92. Wang L, He S, Tu Y, Ji P, Zong J, Zhang J, Feng F, Zhao J, Gao G, Zhang Y. Downregulation of chromatin remodeling factor CHD5 is associated with a poor prognosis in human glioma. J Clin Neurosci. 2013;20(7):958-63.

93. Kennedy NJ, Cellurale C, Davis RJ. A radical role for p38 MAPK in tumor initiation. Cancer Cell. 2007;11(2):101-3.

94. Wong JC, Fiscus RR. Essential roles of the nitric oxide (no)/cGMP/protein kinase $G$ type-la (PKG-la) signaling pathway and the atrial natriuretic peptide (ANP)/CGMP/PKG-la autocrine loop in promoting proliferation and cell survival of OP9 bone marrow stromal cells. J Cell Biochem. 2011;112(3): 829-39.

\section{Publisher's Note}

Springer Nature remains neutral with regard to jurisdictional claims in published maps and institutional affiliations. 